\title{
The use of discourse markers by Afrikaans-speaking preschoolers with and without specific language impairment*
}

\author{
Frenette Southwood \\ Department of General Linguistics, Stellenbosch University, 7600 Stellenbosch, South Africa \\ E-mail: fs@sun.ac.za
}

Matty Carinus and Salomé Engelbrecht

Division of Speech, Language and Hearing Therapy, Stellenbosch University, PO Box 19063, Tygerberg, 7505,

South Africa

\begin{abstract}
Discourse markers (DMs) are words or phrases speakers employ to coordinate what they want to say when, to whom and how during conversation. The purpose of this study was to establish (i) what types of DMs occur in the language of young Afrikaans-speaking children; (ii) what development, if any, takes place in DM use from the age of 4 years to 6 years; and (iii) how, if at all, the use of DMs by children with specific language impairment (SLI) differs from that of typically develping (TD) children. The participants were three Afrikaans-speaking groups: 15 TD 6-year-olds, 15 6-year-olds with SLI, and 15 TD 4-year-olds matched on mean length of utterance with the SLI group. A 30minute spontaneous language sample was obtained from each participant. The number of occurrences of DMs (tokens) and the number of different DMs (types) used during these 30 minutes were tallied for each participant individually and for each of the three groups. It was found that maar 'but', en 'and', ja 'yes', and dan 'then' were some of the most frequently occurring DMs in the three groups. The SLI group used DMs that also occurred in the language of the TD groups, but the SLI group also used DMs which were not used by the TD groups at all. In terms of number of different DMs used, the SLI group functioned at a level between the two TD groups: They used more and a wider range of markers than the 4-year-olds but fewer and a smaller range of markers than their 6-year-old peers. It appears then that the use of DMs shows development between the ages of 4 and 6 years and that the use of DMs is delayed in children with SLI. Appropriate use of DMs can improve listeners' understanding of what is said; as such, it is recommended that speech-language therapists make DMs a focus point during therapy delivery to children with language impairment.
\end{abstract}

Keywords: Specific language impairment, Afrikaans, discourse markers, child language development

\section{Introduction}

Language can be viewed as the act of communication coordinated between its participants (Louwerse and Hite Mitchell 2003:199). By this is meant that speakers need to coordinate what they want to say when, to whom and how. To do so successfully, discourse markers (DMs), amongst other means, are employed. These markers are also referred to as "cue 
phrases", "discourse signalling devices", "discourse connectives", "pragmatic connectives" or "sentence connectives", amongst others (cf. Fraser 1999:932).

Schiffrin (1987:35) refers to DMs as elements that "bracket units of talk", deliberately keeping the definition vague, seeing that precise and detailed definitions tend to be too narrow to include all types of DMs. By bracketing units of language, DMs offer a framework in which comprehension is made easier for the listener. Beukes (2007:23) formulates this as follows: "Discourse markers are one of the most important components that can provide the listener with comprehension". Louwerse and Hite Mitchell (2003:204) further explain that DMs often mark transition points in the discourse. From these definitions, it can be concluded that DMs are the "glue" used by participants during communication to hold the dialogue together (Louwerse and Hite Mitchell 2003:203).

This study examined the use of DMs by young Afrikaans-speaking children with and without Specific Language Impairment ${ }^{1}$ (SLI), and aimed to answer the following research questions:

(i) What types of DMs occur in the language of typically developing young Afrikaansspeaking children and in that of young Afrikaans-speaking children with SLI?

(ii) What development, if any, takes place in the use of DMs from the age of 4 years to 6 years?

(iii) How does the use of DMs by Afrikaans-speaking 6-year-olds with SLI differ from that of typically developing Afrikaans-speaking 4- and 6-year-olds ${ }^{2}$ ?

The first hypothesis was that development takes place in the use of DMs in Afrikaansspeaking children from the age of 4 years to the age of 6 years: It was hypothesised that the typically developing 6-year-olds will use more types of DMs as well as more tokens than the 4-year-olds. The second hypothesis was that the use of DMs by 6-year-olds with SLI will differ from that of their age-matched peers without SLI: The 6-year-olds with SLI will use a smaller number of types of DMs than their typically developing peers and also a smaller number of tokens. The third hypothesis was that the use of DMs by the children with SLI will be similar to that of the typically developing 4-year-olds: The children with SLI will therefore present with a language delay, presenting like younger typically developing children in terms of their use of DMs. Although DMs, as stated above, are also called "pragmatic connectives" and children with Grammatical SLI (such as those who participated in our study) usually do not experience difficulties in the domain of pragmatics, we still predicted that our participants would use fewer DMs than their typically developing peers. We based this prediction on the fact that DMs are specific, and at times rather sophisticated and thus possibly later developing, vocabulary items that need to be acquired, and children with SLI are known to have smaller vocabularies than their typically developing peers (Hick, Botting and Conti-Ramsden 2007).

The paper is structured as follows: Section 2 provides an overview of DMs. In Section 3, an exposition is given of the methodology used to test the hypotheses and to answer the research questions. The results of the study are presented and discussed in Section 4, with Section 5 providing a summary of the results, answers to the research questions, a brief discussion of the limitations of this study, and recommendations for further research on the use of DMs by young Afrikaans-speaking children. 


\section{Discourse Markers}

\section{1 $\quad$ Features of DMs}

DMs have certain features which distinguish them from other language units or grammatical categories. One common feature of DMs is that they often (but not exclusively) occur at the beginning of sentences (Schiffrin 1987:31), in order to link one idea to prior ones (cf. Fraser 1999:938). Another common feature of DMs is that they are mostly conjunctions, adverbs or prepositional phrases (Fraser 1999:943), but there are also DMs such as you know and I mean which are difficult to categorise (Schiffrin 1987:40). Furthermore, DMs are said to form a pragmatic class, as they contribute to the interpretation of an utterance within a specific context. As such, DMs have an emotive, rather than a referential, function (Carstens 1997:308).

A further feature of DMs is that they can be omitted from an utterance without causing the sentence to lose its core meaning; the force of the utterance will, however, be less clear should such an omission take place (Norrick 2001:850). Schiffrin (1987:320-321) states that if DMs are not present, there could be one of many relationships between two utterances. When DMs are used, however, there can only be one possible relationship between the two utterances. Another feature of DMs is that, on their own, they do not have any social and/or expressive meaning. Rather, they must be interpreted in context and, more specifically, within a specific utterance (cf. Schiffrin 1987:318). A last feature of DMs is that they can perform different functions (Müller 2005:8-9), some of which will be discussed in Section 2.2.

\subsection{Functions of DMs}

The general function of a DM is that it represents a certain relationship between the segment of which it forms a part and another segment (Fraser 1999:938). Various models are used to represent the different functions of DMs. Schriffrin's (1987) model, which uses five so-called "planes" to explain the different functions which a DM can perform, will be used here, as this is the model which is most commonly referred to in the literature. The explanation given below of Schriffrin's model draws on Fraser's (1999:934) exposition of this model. In order to demonstrate that one DM can have many functions, the DM well will be used to demonstrate each of Schiffrin's (1987) five planes.

The first plane of conversation on which DMs function is that of the ideational structure. All DMs necessarily function on this plane. Here DMs bind different ideas together. In the following conversational turn, the word well in each instance links one idea to the previous one: "They're getting married in April. Well, that's what I heard. I think it's a great time of year. Well, I got married then."

The second plane is that of the information state. This plane pertains to the knowledge that both the speaker and the hearer possess as well as the knowledge that they do and do not have about each other. Consider the following example:

\section{Speaker A: "They're getting married in April."}

Speaker B: "Well, that's good news."

Here, the word well indicates that the information in Speaker A's utterance is information that Speaker B did not possess. 
The third plane is that of participation. This is the primary plane on which well functions, as well is mostly used to indicate a speaker as a respondent, i.e., well usually indicates that the speaker is going to react to something said by the conversational partner. For instance, if Speaker A suggests a solution to a problem, well in Speaker B's reply "Well, I think that is the answer" indicates that Speaker B is about to react directly to the suggestion of Speaker A.

The action stucture is the fourth plane and refers to any speech act in the previous segments or to speech acts in forthcoming segments. Should a speaker not be able to oblige to a request, well could be used by the speaker in the following manner: "Well, that will be difficult for $m e^{\prime \prime}$.

The last plane is the exchange structure. This entails the roles of the participants as well as the alternation of roles between participants. On this plane, DMs are used to indicate that the speaker wishes to continue with a conversational turn or that the speaker has ended his/her turn. For instance, in "I think we should go to the beach on Saturday. Well, we'll have to see about the weather of course", the DM well indicates that the speaker wishes to continue with his/her turn and is not yet ready to give the floor to the conversational partner.

\subsection{Types of DMs}

Beukes (2007:23-25) lists the following nine types of DMs:

(i) additive DMs, which indicate that information will be added to that which the speaker has already said, such as and, furthermore or equally important;

(ii) illustrative and explanatory DMs, which indicate that an explanation or illustration is about to follow, such as for example, specifically or to illustrate;

(iii) resumptive DMs, the use of which allows the speaker to paraphrase a previous utterance or to reintroduce a particular idea, such as again, in other words or thus;

(iv) contrastive DMs, which indicate that the speaker longs to present an idea to the listener which contrasts with a previously presented idea, such as but (what about), on the other hand or to the contrary;

(v) cause-and-effect DMs, which introduce the cause or the consequence of an event or an idea, such as therefore, because of or consequently;

(vi) conditional DMs, which introduce the conditions under which the previous utterance should be considered, indicating specific requirements, such as although, if or unless;

(vii) emphasising DMs, which are used to stress the importance of a specific utterance, and by doing so immediately request the listener's attention, such as above all, the gist of the matter being or note that;

(viii) ordering DMs, which are used to place the ideas contained in utterances in a certain order, such as next, then, previously or to conclude; and

(ix) summarising DMs, which, as the term suggests, are used to indicate that a summary of ideas or information will be given and, as such, often occur towards the end of a conversational turn, such as in short, in conclusion or to summarise.

\subsection{Development of DMs in child language}

Several studies of DMs have focused on the development of DMs in child language. There are many studies on the development of DMs in the language of English-speaking children. For instance, Gallagher and Craig (1987) examined the use of DMs by 4-year-olds and found that most DMs are used to link two speech acts. These authors performed a follow-up study with 
the same group of children two years later and found that the various functions for which DMs are used remain constant between the ages of 4 and 6 years (Craig and Gallagher 1988: 181). Kyratzis and Ervin-Tripp (1999) compared the use of DMs by 4- and 7-year-olds in various contexts. Firstly, the children were required to retell a story to a friend and secondly, the children had to play with the friend. The authors found that the children's use of DMs differed according to the context. Furthermore, the younger children used markers to a lesser extent than the older children did, and girls' and boys' use and functions of DMs also differed in terms of the types of markers preferred by each gender. Regarding this latter preference, Escalera (2009) found that when one controls for the activity in which the children are involved, there were significant differences in the DM functions used by the two genders during role-play: Boys used far more exchange and action structures than girls did.

In languages other than English, the acquisition of DMs has been studied to a lesser extent. Furman and Özyürek (2007) compared the use of the Turkish equivalents of uuhh, I mean and $y^{\prime}$ know by Turkish-speaking children to that of adult speakers of the language. These authors found that the frequency and function of DMs change with age. Children mostly use DMs to organise their utterances whereas adults mainly use DMs more interactively. The DMs of children and adults thus perform different functions. Furthermore, DMs are already present in the language of 3-year-olds, but the development of DMs continues even after the age of 9 years (Furman and Özyürek 2007:1756). Meng and Schrabback (1999) studied the conversations between German-speaking 3- to 4-year-olds and adults. They found that children are less aware, and have a more limited comprehension, of the different functions that DMs can perform. Andersen, Brizuela, DuPay and Gonnerman (1999) compared the acquisition of DMs by American, French and Spanish children. They found that by the time they reach school-going age, children in all three cultures are sensitive to the use of DMs.

No similar studies on the DMs of Afrikaans-speaking children have yet been conducted and no studies on the use of DMs by children with language disorders could be traced. For these reasons, a study was done to answer the questions set out in Section 1.

\section{Methodology}

\subsection{Research design}

A quantitative research design was used to calculate (i) the number of types and (ii) the number of tokens of DMs used by Afrikaans-speaking children with SLI and by typically developing Afrikaans-speaking 4- and 6-year olds. Several measures of DM use by the three groups were thus quantified, and frequency counts of this use were then compared within and between the three participant groups.

\subsection{Participants}

The first participant group (TD4) consisted of 15 typically developing Afrikaans-speaking 4year-olds, of which seven were male and eight female. Their average age was 4.34 years, with individual ages ranging from 4 years 0 months to 4 years 7 months. Their mean length of utterance measured in words (MLUw) was 4.56, with a range of 3.91 to 5.00. The second group (TD6) comprised 15 typically developing Afrikaans-speaking 6-year-olds (six male and nine female) between the ages of 6 years 2 months and 6 years 11 months, with an average age of 6.56 years. Their MLUw was 5.92, ranging from 5.12 to 7.10. According to the parents and teachers of these two groups of participants, the children were typically developing in all 
respects. Their language, intellectual and socioemotional development was thus taken to be age-appropriate. Furthermore, there were no signs of hearing problems or neurological damage. In the TD4 group, all participants were White, and of the TD6 participants, 13 were White and two were Coloured. ${ }^{3}$

The last group consisted of 15 Afrikaans-speaking 6-year-olds with SLI, seven male and eight female. Their ages ranged from 6 years 0 months to 6 years 11 months, with a mean of 6.48 years. Their average MLUw was 4.35, with a range from 3.54 to 5.79 . In each case, a diagnosis of SLI was made by the participant's speech-language therapist. Three participants in the SLI group were Coloured and 12 were White.

\subsection{Procedures}

Participants were recruited by contacting schools and daycare centres or speech-language therapists, who referred the first author to the parents. Parents were then provided with written information on the study, a consent form and a blank case history questionnaire containing questions about, amongst other things, their child's speech, language and hearing status and their child's general as well as language development. Of those typically developing participants whose parents completed case history questionnaires and gave written consent, fifteen 4- and fifteen 6-year-olds were randomly selected. The first 15 qualifying children with SLI referred by their therapists were included in the study. All participants passed a hearing screening test (ASHA 1997-2009), and IQ testing of the participants with SLI rendered scores of 85 or above in each case.

After these tests, a spontaneous language sample of 30 minutes was obtained from each participant by the first author. The context of the conversation (whether informal or formal) influences the use of DMs, with informal contexts tending to elicit more DMs than formal contexts do (cf. Biber 1988). For these reasons, language samples were all collected under the same, informal conditions, namely during freeplay with figurines, their accessories (such as hats, rucksacks and two-way radios), plastic toy furniture and wooden building blocks. All samples were recorded using a visible tape recorder and were later transcribed orthographically by the first author, after which the MLUw for each participant was calculated. Three samples (that of one child per group of participants) were independently transcribed by a final-year speech-language and hearing therapy student; intertranscriber reliability was $97 \%$. The MLUw for each of the 45 language samples was also calculated independently by this student and yielded an interrater reliability of $94 \%$.

Next, the following was determined for each sample separately and then for each participant group separately: (i) the number of different types of DMs occuring in the samples and (ii) the frequency with which each of these DMs occur, i.e., the number of tokens of each type of DM. This tallying was done by the second and third authors, both final-year speech-language and hearing therapy students at the time of the study. Initially, each author independently tallied the DMs in two language samples. Hereafter, the scores obtained by each author were compared and any differences in scores were resolved by revisiting the transcripts and tallying the occurrence of the particular marker together. After these training analyses, the second author analysed 21 transcripts and the third author 22 transcripts. After completion of this, each of these authors independently reanalysed three transcripts (one from each of the participant groups) originally analysed by the other. This was done to determine whether the two authors indeed used the same criteria throughout. The interrater reliability was then 
calculated by tallying, for all DMs examined in this study (cf. Table 1), the number of times the word concerned was indeed used as a DM according to each of the two authors, and then dividing the score of the lowest rating author by that of the highest rating author. The mean interrater reliability across the three samples was 97 when expressed as a percentage.

\subsection{DMs examined in this study}

Table 1 presents an alphabetically arranged list of the DMs examined in the language samples of the participants. This list was compiled by combining the markers mentioned in various sources, namely Bergerson (2002), Beukes (2007), Carstens (1997), Fraser (1999), Kruger (2004), Louwerse and Hite Mitchell (2003), Norrick (2001), Roberge (2002) and Schiffrin (1987), and translating them into Afrikaans. English translations of each marker are provided in parentheses (note that some DMs are English words frequently used in Afrikaans). In the case of those markers that require a particular context before their meaning can be understood, such a context is provided in Afrikaans and translated into English; contexts marked with a hash comprise actual utterances produced by the participants.

Table 1. Discourse markers examined in the language samples of the participants

\begin{tabular}{|c|c|c|}
\hline \multirow{2}{*}{$\begin{array}{l}\text { aan die ander kant 'on the } \\
\text { other hand' }\end{array}$} & jip 'yup, meaning "yes" & of 'or' \\
\hline & Juffrou 'Teacher / Miss' & okei 'okay' \\
\hline actually 'actually' & jy weet 'you know' & omdat 'because' \\
\hline alhoewel 'although' & kyk 'look' & o okei 'oh okay' \\
\hline oraait 'all right' & laat ek sien 'let me see' & presies! 'exactly!' \\
\hline anders 'otherwise' & laat my sien 'let me see' & reg 'right' \\
\hline anyway 'anyway' & later 'later' & sedert '(ever) since' \\
\hline as 'if' & luister 'listen' & selfs 'even' \\
\hline asseblief 'please' & maar 'but' & sien 'see' \\
\hline behalwe 'except' & maar dan 'but then' & sies 'sis / yuck' \\
\hline beslis 'definitely' & maar toe 'but then' & sjoe 'wow' \\
\hline boonop 'on top of that' & man 'man' & SO 'so' \\
\hline boy! 'boy!' & miskien 'maybe' & soort van 'sort of' \\
\hline \multirow{2}{*}{$\begin{array}{l}\text { byvoorbeeld 'for example / } \\
\text { for instance' }\end{array}$} & $m m$ 'mm' & soos 'like' \\
\hline & moontlik 'possibly' & soos in 'like in / as in' \\
\hline daarom 'therefore' & môre 'morning' & steeds 'still' \\
\hline dan 'then' & \multirow{7}{*}{$\begin{array}{l}\text { mos (sentential adverb } \\
\text { with no English } \\
\text { equivalent): \#Maar as ek } \\
\text { groot is, dan werk dit } \\
\text { mos 'But if I'm big, it is } \\
\text { the case that it will work } \\
\text { out, hey?' }\end{array}$} & sure 'sure' \\
\hline dis okei 'it's okay' & & \multirow{4}{*}{$\begin{array}{l}\text { Tannie 'Auntie' (a common } \\
\text { term of address used for } \\
\text { women older than the } \\
\text { speaker) }\end{array}$} \\
\hline dis reg 'that's right' & & \\
\hline dus 'thus' & & \\
\hline egter 'however' & & \\
\hline ek bedoel 'I mean' & & tensy 'unless' \\
\hline ek raai 'I guess' & & terwyl 'while' \\
\hline ek wed (jou) 'I bet (you)' & na 'after' & totsiens 'goodbye' \\
\hline en 'and': \#En hier's lekker um & nadat 'after' & $u h$ 'uh', meaning "yes" \\
\hline $\begin{array}{l}\text { koppies vir ons 'And here are } \\
\text { nice um cups for us' }\end{array}$ & $\begin{array}{l}\text { natuurlik 'naturally / } \\
\text { obviously' }\end{array}$ & $\begin{array}{l}\text { uh-huh 'uh-huh', meaning } \\
\text { "yes" }\end{array}$ \\
\hline en buitendien 'and in any & nee 'no' & wel 'well' \\
\hline
\end{tabular}




\begin{tabular}{|c|c|c|}
\hline case' & nee! 'no!' & weer 'again' \\
\hline goed! 'good!' & netso 'likewise' & whatever 'whatever' \\
\hline Goeie môre 'good morning' & nog steeds 'still' & wow 'wow' \\
\hline hallo 'hello' & nou 'now' & verder 'furthermore / also' \\
\hline \multirow{2}{*}{$\begin{array}{l}\text { huh-uh 'huh-uh', meaning } \\
\text { "no"' }\end{array}$} & \multirow{2}{*}{$\begin{array}{l}\text { nou goed 'okay / fine / } \\
\text { right' }\end{array}$} & volgende 'next' \\
\hline & & voorheen 'previously' \\
\hline in daardie geval 'in that case' & nou-ja 'well / oh well' & \multirow{2}{*}{$\begin{array}{l}\text { waa! 'wha!', exclamation of } \\
\text { shock or surprise }\end{array}$} \\
\hline in elk geval 'in any case' & $o$ 'oh' & \\
\hline in hierdie geval 'in this case' & \multirow{2}{*}{$\begin{array}{l}\text { obviously 'naturally / } \\
\text { obviously' }\end{array}$} & wanneer 'when' \\
\hline ja 'yes' & & want 'because' \\
\hline intussen 'in the meantime' & $o e$ 'ooh' & wat! 'what!' \\
\hline
\end{tabular}

\subsection{Ethical considerations}

Permission to perform the study was obtained from the Western Cape Education Department, the Ethics Committee of the Research Committee of Tygerberg Hospital (where some of the children with SLI received speech-language therapy) and the head teachers concerned. Parents of all participants gave written informed consent for their children's participation in the study. The parents were informed that all information obtained on and from their children would be treated as strictly confidential and that the data would be used for academic purposes only. Parents were also informed that they or their children could withdraw consent at any time. Children were informed that they could request to rest at any stage during the proceedings and that they could also opt to terminate their participation in the study without having to provide a reason for their decision. Children were also given pseudonyms in order to ensure anonimity.

\section{Results and discussion}

The obtained results are summarised in Table 2 and will be discussed in the following order: use of DMs by each of the groups separately, followed by a comparision of DM use by the three groups. Please refer to Table 2 throughout the discussion of the results. 
Table 2. The use of discourse markers by the TD4, TD6 and SLI groups

\begin{tabular}{|c|c|c|c|c|c|c|}
\hline \multirow[t]{2}{*}{ Group } & \multirow{2}{*}{$\begin{array}{c}\text { Total } \\
\text { no. of } \\
\text { types } \\
\text { of } \\
\text { DMs }\end{array}$} & \multirow{2}{*}{$\begin{array}{c}\text { Total } \\
\text { no. of } \\
\text { tokens }\end{array}$} & \multicolumn{2}{|c|}{$\begin{array}{l}\text { Range of any DMs within the } \\
\text { group }\end{array}$} & \multirow{2}{*}{$\begin{array}{c}3 \text { markers } \\
\text { with highest } \\
\text { occurrence }\end{array}$} & \multirow{2}{*}{$\begin{array}{c}6 \text { markers } \\
\text { with highest } \\
\text { occurrence }\end{array}$} \\
\hline & & & $\begin{array}{c}\text { Minimum no. } \\
\text { of occurrences } \\
\text { of any type of } \\
\text { DM }\end{array}$ & $\begin{array}{c}\text { Maximum no. } \\
\text { of occurrences } \\
\text { of any type of } \\
\text { DM }\end{array}$ & & \\
\hline TD4 & 33 & 988 & 1 & 35 & $\begin{array}{l}\text { maar 'but' } \\
\text { en 'and' } \\
\text { ja 'yes' }\end{array}$ & $\begin{array}{l}\text { maar 'but' } \\
\text { en 'and' } \\
\text { ja 'yes' } \\
\text { dan 'then' } \\
\text { nou 'now' } \\
\text { nee 'no' }\end{array}$ \\
\hline TD6 & 48 & 1913 & 1 & 57 & $\begin{array}{l}\text { maar 'but' } \\
\text { en 'and' } \\
\text { dan 'then' }\end{array}$ & $\begin{array}{l}\text { maar 'but' } \\
\text { en 'and' } \\
j a^{\mathrm{a}} \text { 'yes' } \\
\text { dan 'then' } \\
\text { so 'so' } \\
\text { want } \\
\text { 'because' } \\
a s^{\mathrm{a}} \text { 'as' }\end{array}$ \\
\hline SLI & 42 & 1345 & 1 & 73 & $\begin{array}{l}\text { en 'and' } \\
\text { ja 'yes' } \\
\text { dan 'then' }\end{array}$ & $\begin{array}{l}\text { maar 'but' } \\
\text { en 'and' } \\
\text { ja 'yes' } \\
\text { dan 'then' } \\
\text { nou 'now' } \\
\text { so 'so' }\end{array}$ \\
\hline
\end{tabular}

a $j a$ 'yes' and $a s$ 'if' had the same frequency of occurrence (number of tokens) in the TD6 group.

\subsection{Use of DMs by the typically developing 4-year-olds}

The TD4 group used 33 different types of DMs in total, with a range of 6 to 17 types of markers for the group as a whole. The total number of tokens used by the group as a whole was 988 , whereas the range of the total number of tokens was 25 to 175 DMs.

The three markers used most frequently by the TD4 group were maar 'but', en 'and' and ja 'yes', and the next three most frequently used ones were nee 'no', nou 'now' and dan 'then'. Although en 'and' was the DM of preference for this group as a whole, not all of the members of this group used en 'and' with the same frequency and certain members showed preference for other DMs as well. For example, one 4-year-old boy (NIC) used en 'and' as a DM only once in his 30-minute language sample but used kyk 'look' (which was only used once by one other member of this group) 20 times. ILA, a typically developing 4-year-old girl, was the only participant in any of the three groups not to use en 'and' (the DM with the highest frequency of use in all three groups) at all.

The following nine DMs were used only once by the TD4 group: anders 'otherwise', Juffrou 'Teacher / Miss', asseblief 'please', hallo 'hello', Tannie 'Auntie', wel 'well', and maar dan 'but then' (by three girls); and maar toe 'but then' and sies 'sis'/'yuck' (by two boys). The following 
DMs were used by only two members of the TD4 group: kyk 'look', miskien 'maybe' netso 'likewise', omdat 'because' and uh-huh 'uh-huh' (each by one girl and one boy, in total four different girls and two different boys).

The above-mentioned 14 DMs serve as an indication of DMs used by the individual participants in this study, in addition to those markers popular with the specific group of 4year-olds as a whole. There were no notable differences in the frequency with which boys and girls used these additional DMs.

Furthermore, it appears as though 4-year-olds are already capable of using words as DMs (i.e., to indicate the relationship between two segments) and also that they are able to use one word as different types of DMs (i.e., fulfilling different pragmatic functions) in their utterances. Two consecutive utterances of a 4-year-old girl illustrate this use of one word (in this case, maar 'but') for different functions:

\section{Utterance 1: Hulle kan sit maar net nie staan nie They can sit but they just cannot stand \\ Utterance 2: $\quad$ Maar die grotes kan staan \\ But the big ones can stand}

In utterance 1, maar 'but' is used as a contrastive DM (cf. Beukes 2007:24) because two concepts are placed in opposition to each other. Utterance 2 is illustrative of the use of an additive DM, in the sense that maar links the second utterance to the first and provides information which follows on that provided in utterance 1 .

\subsection{Use of DMs by the typically developing 6-year-olds}

In total, the TD6 group made use of 48 types of DMs, with a range of 11 to 26 types of markers used by individuals in the group. A total number of 1913 tokens was used by the group as a whole. The range of these tokens was from 47 to 209.

The six DMs used the most frequently were en 'and', maar 'but', dan 'then', so 'so' and want 'because', with $j a$ 'yes' and as 'if' sharing sixth place. The three markers with the highest frequency of occurrence were en 'and', maar 'but', and dan 'then' (cf. Table 2).

Twelve DMs were used only once by the 6-year-old group as a whole. Of these, seven were used only by boys (five boys in total). These DMs were behalwe 'except', daarom 'therefore', dis okei 'it's okay', dis reg 'that's right', selfs 'even', totsiens 'goodbye' and voorheen 'previously'. The remaining five DMs were Juffrou 'Teacher / Miss', sjoe 'wow', verder 'furthermore / also', wel 'well' and wow 'wow' and were each used by a girl (two girls in total). The following six markers were used only by the individuals in the TD6 group: anders 'otherwise' (by two girls), and asseblief 'please', ek bedoel 'I mean', man 'man', nog steeds 'still' and $u h$-huh 'uh-huh', meaning "yes" (each by one boy and one girl, in total three different boys and two different girls). From the above, it would appear as though certain children have a preference for so-called "unpopular" DMs.

The DM of preference of the TD6 group was en 'and', but this was not the first choice of every individual in this group. For instance, one typically developing 6-year-old boy preferred maar 'but' and dan 'then' over en 'and'. From this, one can deduce that although many 
individuals use the same top six DMs, there are still individual differences, amongst others in the frequency of use ranking of these top six markers.

\subsection{Use of DMs by the 6-year-olds with SLI}

The SLI group used 42 different types of DMs in total, with a range of 9 to 24 types in the group as a whole. The total number of tokens used by this group was 1345 . The range of the total number of tokens was from 31 to 225 .

The three most frequently used markers were dan 'then', en 'and' and ja 'yes', and the next three most frequently used ones were so 'so', nou 'now' and maar 'but' (cf. Table 2). The DM of preference for the SLI group was en 'and', but this was not the most frequently used marker by every member of this group. It was, however, the case for IVA, a 6-year-old boy with SLI. He used en 'and' 73 times, which far exceeds the highest occurrence of en 'and' in both of the other groups. Furthermore, IVA's score for en 'and' does not correlate with that of the average use of $e n$ 'and' by his group.

The following DMs were used only once by the SLI group: asseblief 'please', behalwe 'except', dis okei 'it's okay', †jy weet 'you know', miskien 'maybe', nog steeds 'still', †nou-ja 'well' and verder 'furthermore / also' (each of these used by a girl, in total four different girls), and †jip 'yup' meaning "yes", †later 'later', maar dan 'but then', †môre 'morning', †na 'after', netso 'likewise', †o okei 'oh okay' and wow 'wow' (by five different boys in total). The following DMs were used only twice by the 6-year-olds with SLI: man 'man' and †reg 'right' (each by a girl and a boy; in total two different girls and two different boys) en sjoe 'wow' (by two boys).

Those markers preceded by $\dagger$ (†jy weet 'you know', †nou-ja 'well', †jip 'yup', †later 'later', † môre 'morning', †na 'after', †o okei 'oh okay' and †reg 'right') were only used by the SLI group, not by the two typically developing groups. Some of these DMs are generally found more often in literacy-related language and are also representative of language of a higher level of development (Furman and Özyürek 2007). Possible explanations for the use of these DMs by the SLI group include the following:

(i) It could be that the first author used some of these markers during her interaction with the SLI group but not the other two groups; this is a possibility not investigated in the present study. One example of a DM frequently used by the first author is reg 'right'. The group could therefore have imitated this DM used by their adult conversational partner.

(ii) It is possible that the children heard the DMs in question in a different situation (i.e., not necessarily during the language sample elicitation activities) and that they now used these DMs in an imitatory manner, without (full) comprehension of the meaning of such markers.

(iii) Fourteen of the 15 individuals in the SLI group were receiving speech-language therapy at the time of language sample collection. A last possibility, therefore, is that their speech-language therapists have frequently modelled the use of such DMs to them. Note, however, that one girl (CHA) whose language was severely impaired at the time of data collection did not receive speech-language therapy - her parents cited financial reasons for deciding against therapy after receiving the initial diagnosis. CHA made use of 15 types of DMs and 57 tokens in total. Her scores compare favourably to the average performance of the rest of her group, which reduces the 
possibility of the children benefitting from modelling by their speech-language therapists.

\subsection{Comparison of DM use by the three groups}

The total number of types of DMs used by the TD4, the TD6 and the SLI group was 33, 48 and 42 markers, respectively, and the total number of tokens used was 988, 1913 and 1345, respectively (cf. Table 2). The number of types and the number of tokens used by the SLI group were thus at a level between those of the TD4 and the TD6 group.

The DM used most frequently by all three groups was en 'and'. Four DMs appeared in the six most frequently used markers by each of the three groups, namely maar 'but', en 'and', $j a$ 'yes' and dan 'then'. In the TD4 and SLI groups, the DM nou 'now' formed part of the six DMs with the highest number of occurrences, but not in the TD6 group. Further, the DM so 'so' occurred in both the TD6 and SLI groups as one of the six most frequently used markers, but not in the TD4 group. The 4-year-olds were the only group not to have nee 'no' among their top six markers, whereas the TD6 group was the only to include want 'because' and as 'as' in their top six (see Table 2 for a more detailed inter-group comparison).

All top six DMs used by the SLI group were also used by the TD4 and/or TD6 group. The finding that the SLI group does share top six DMs with the other two groups could be seen as an indication of the SLI group's functioning at a level somewhere between the two typically developing groups.

The types of DMs used at least once by each group are listed in Table 3. This table provides an overview of the variety found within the use of DMs by the three groups. For the sake of simplicity, frequency counts are not offered here, but there were indeed differences in the frequency with which some markers were used by the three groups. For instance, the SLI group used Juffrou 'Teacher' 24 times whereas the other two groups each used it only once.

Table 3. Comparison of discourse markers use by the three groups

\begin{tabular}{|c|c|c|c|c|c|c|c|}
\hline \multirow{2}{*}{$\begin{array}{l}\text { Discourse } \\
\text { marker }\end{array}$} & \multicolumn{3}{|c|}{ Used by } & \multirow{2}{*}{$\begin{array}{l}\text { Discourse } \\
\text { marker }\end{array}$} & \multicolumn{3}{|c|}{ Used by } \\
\hline & TD4 & TD6 & SLI & & TD4 & TD6 & SLI \\
\hline 1. anders & $\Omega^{a}$ & $\checkmark$ & & 29. nee & $\checkmark$ & $\checkmark$ & $\checkmark$ \\
\hline 2. as & $\checkmark$ & $\checkmark$ & $\checkmark$ & 30. netso & $\checkmark$ & $\checkmark$ & $\checkmark$ \\
\hline 3. asseblief & $\checkmark$ & $\checkmark$ & $\checkmark$ & 31. nog steeds & & $\checkmark$ & $\checkmark$ \\
\hline 4. behalwe & & $\checkmark$ & $\checkmark$ & 32. nou & $\checkmark$ & $\checkmark$ & $\checkmark$ \\
\hline 5. daarom & & $\checkmark$ & & 33. nou-ja & & & $\checkmark$ \\
\hline 6. dan & $\checkmark$ & $\checkmark$ & $\checkmark$ & 34. $o$ & $\checkmark$ & $\checkmark$ & $\checkmark$ \\
\hline 7. dis ok & & $\checkmark$ & $\checkmark$ & 35. oe & $\checkmark$ & $\checkmark$ & $\checkmark$ \\
\hline 8. dis reg & & $\checkmark$ & & 36. of & $\checkmark$ & $\checkmark$ & $\checkmark$ \\
\hline 9. ek bedoel & & $\checkmark$ & & 37. ok & $\checkmark$ & $\checkmark$ & $\checkmark$ \\
\hline 10.en & $\checkmark$ & $\checkmark$ & $\checkmark$ & 38. omdat & $\checkmark$ & $\checkmark$ & \\
\hline 11. goed & & & $\checkmark$ & 39. o ok & & & $\checkmark$ \\
\hline 12. hallo & $\checkmark$ & $\checkmark$ & $\checkmark$ & 40. reg & & & $\checkmark$ \\
\hline 13. huh-uh & $\checkmark$ & $\checkmark$ & $\checkmark$ & 41. selfs & & $\checkmark$ & \\
\hline 14. ja & $\checkmark$ & $\checkmark$ & $\checkmark$ & 42. sies & $\checkmark$ & & \\
\hline 15. jip & & & $\checkmark$ & 43. sjoe & & $\checkmark$ & $\checkmark$ \\
\hline 16. juffrou & $\checkmark$ & $\checkmark$ & $\checkmark$ & 44. so & $\checkmark$ & $\checkmark$ & $\checkmark$ \\
\hline
\end{tabular}




\begin{tabular}{|c|c|c|c|c|c|c|c|}
\hline \multirow{2}{*}{$\begin{array}{l}\text { Discourse } \\
\text { marker }\end{array}$} & \multicolumn{3}{|c|}{ Used by } & \multirow{2}{*}{$\begin{array}{l}\text { Discourse } \\
\text { marker }\end{array}$} & \multicolumn{3}{|c|}{ Used by } \\
\hline & TD4 & TD6 & SLI & & TD4 & TD6 & SLI \\
\hline 17. jy weet & & $\checkmark$ & $\checkmark$ & 45. soos & $\checkmark$ & $\checkmark$ & $\checkmark$ \\
\hline 18. kyk & $\checkmark$ & $\checkmark$ & & 46. soos in & & $\checkmark$ & \\
\hline 19. later & & & $\checkmark$ & 47. tannie & $\checkmark$ & $\checkmark$ & $\checkmark$ \\
\hline 20. maar & $\checkmark$ & $\checkmark$ & $\checkmark$ & 48. totsiens & & $\checkmark$ & \\
\hline 21. maar dan & $\checkmark$ & $\checkmark$ & $\checkmark$ & 49. uh & $\checkmark$ & $\checkmark$ & $\checkmark$ \\
\hline 22. maar toe & $\checkmark$ & $\checkmark$ & & 50. uh-huh & $\checkmark$ & $\checkmark$ & $\checkmark$ \\
\hline 23. man & $\checkmark$ & $\checkmark$ & $\checkmark$ & 51. verder & & $\checkmark$ & $\checkmark$ \\
\hline 24. môre & & & $\checkmark$ & 52. voorheen & & $\checkmark$ & \\
\hline 25. mos & $\checkmark$ & $\checkmark$ & $\checkmark$ & 53. wanneer & & $\checkmark$ & \\
\hline 26. miskien & $\checkmark$ & $\checkmark$ & $\checkmark$ & 54. want & $\checkmark$ & $\checkmark$ & $\checkmark$ \\
\hline 27. $\mathrm{mm}$ & $\checkmark$ & $\checkmark$ & $\checkmark$ & 55. wel & $\checkmark$ & $\checkmark$ & \\
\hline 28. $n a$ & & $\checkmark$ & $\checkmark$ & 56. wow & & $\checkmark$ & $\checkmark$ \\
\hline
\end{tabular}

${ }^{a}$ Note: $" \checkmark$ " indicates that the marker concerned was used at least once by that particular group.

When considering individual participants, it is notable that each child in the three groups had a specific preferred DM. However, this DM was not necessarily the DM of choice for the group as a whole. The individual who used the highest number of tokens was a 6-year-old boy with SLI (FRA), with 225 tokens in total. However, the individual who used the highest number of types (and thus the greatest variety of markers) was a typically develping 6-yearold girl. From this, one can deduce that although the SLI group uses many tokens in their utterances, they - unlike the TD6 group - do not use more different types of markers. This deduction concurs with one of the findings of Klop and Tuomi's (2007) study, namely that children with a language delay, over time, do use more words in their sentences, but not more types of words. These children's utterances thus become longer but not more complex.

\section{Conclusion}

In summary, maar 'but', en 'and', $j a$ 'yes', and dan 'then' were the four most frequently occurring DMs in the spontaneous language of Afrikaans-speaking typically developing 4and 6-year-olds as well as 6-year-olds with SLI. The SLI group made use of DMs occurring in the language of both the typically developing 4-year-olds and the typically developing 6year-olds, but also used DMs which were not used by any of the typically developing groups. In terms of number of different DMs used, the SLI group functioned at a level between the two typically developing groups: They used a wider range of markers than the 4-year-olds but a smaller range than the typically developing 6-year-olds. In total, the SLI group also used more tokens than the 4-year-olds but fewer than the typically developing 6-year-olds.

As predicted by Hypothesis 1, development in the use of DMs did take place in the Afrikaansspeaking children from the age of 4 to 6 years who participated in this study: The 4-year-olds used 33 different types of DMs and the 6-year-olds 48 different types. The 6-year-olds also used almost double the number of tokens used by the 4-year-olds: 1913 compared to 988.

Furthermore, the 6-year-olds with SLI did indeed perform differently than the typically developing 6-year-olds, as predicted by Hypothesis 2. The former group used 42 types of markers compared to the 48 of the latter group, and the children with SLI used 1345 tokens 
compared to the 1913 of their typically developing peers. However, in contrast to what was predicted by Hypothesis 3, the children with SLI did not present like younger typically developing children. Although their DMs partially agreed with those used by both typically developing groups (especially in terms of their top six markers of preference), children with SLI also made use of markers not used by the other two groups, in particular jy weet 'you know', nou-ja 'well', jip 'yup', later 'later', môre 'morning', na 'after', o okei 'oh okay' and reg 'right'. The children with SLI thus not only showed delayed language development in terms of the use of DMs, but also showed signs of different language development. That said, it is unlikely that DM use can act as a clinical marker of SLI in Afrikaans - where a clinical marker of SLI is defined as "a linguistic form, or principle that can be shown to be characteristic of children with specific language impairment" (Rice, Wexler and Herschberger 1998:1412) - seeing that their use of DMs was still quantitatively better than those of typically developing language-matched children.

There are several limitations to this study, which decreases the generalisability of the results. The first is that, due to the possibility of using one DM in several ways, the identification of DMs in language samples was somewhat subjective at times. The second was that several individuals in the SLI group presented with severely deviant syntax, which reduced the intelligibility of their utterances, which in turn could have influenced the identification of DMs negatively. A third limitation is that only those DMs discussed in the literature were included in this study. As there are Afrikaans DMs on which little (if anything) has been published, the list of Afrikaans markers examined in this study was not exhaustive. Future studies should include such additional markers, for instance darem (which is difficult to translate into English but could mean 'indeed', 'at least' or 'really', depending on the context in which it is used) and en dan 'and then'.

Despite the limitations of this study, the results contribute to the still-limited body of knowledge on DMs in the language of non-English-speaking children and of children with atypical language development. The results also have an implication for clinical practice. The use of DMs by children with SLI does not demonstrate what Rice (2003) called a "delaywithin-delay". A delay-within-delay would entail that children with SLI are "slow getting started" (Rice 2003:73) with using DMs, compared to age-matched controls, and that they furthermore exhibit a delay beyond what one would expect for their level of language development compared to typically developing language-matched children. Given that the children with SLI clearly presented with a delay but were not outperformed by the 4-year-olds with whom they were matched in terms of MLU, DMs cannot be viewed as an area of disproportionate difficulty for children with SLI. Yet, it may be worthwhile to pay attention to the acquisition of DMs during therapy, as the appropriate use of such markers can increase the coherence of the discourse of children with SLI (cf. Beukes 2007:23) as well as their apparent conversational fluency.

Recommendations for future studies include that the DMs used by the three groups are further analysed in terms of their functions, as set out by Beukes (2007:23-25). Also, the DMs used by the three groups of children can be compared to those occurring in utterances of their conversational partner during language sample elicitation as well as to those of their parents. This would enable researchers to establish whether Afrikaans-speaking children's use of DMs is representative of that of adult speakers of the language and also whether there is a priming 
effect for the use of DMs, i.e., whether the DMs used by the communication partner influence those used by the child.

* This material is based on work financially supported by The National Research Foundation of South Africa. Any opinion, findings, conclusions or recommendations expressed in this material are those of the author and therefore the NRF does not accept any liability in regard thereto.

\section{Notes}

1. Specific language impairment is a significant developmental impairment in the language ability of children in the absence of identifiable causal factors or obvious accompanying factors, such as neurological deficits, mental challenges, hearing disabilities, and emotional or behavioral problems (Leonard 1998:vi; Stark and Tallal 1981).

2. The 6-year-olds with SLI were compared to 4-year-olds, amongst others because other studies have found that children with language impairment function at the language level of typically developing children two years younger. In one such study, Rice, Redmond and Hoffman (2006) found that by the time children with SLI enter school, the average length of the utterances which they produce are the same as that of the utterances produced by typically developing children who are two years younger than them. This finding was confirmed by that of Rice's (2003) study.

3. The term "Coloured" is used to refer to people of mixed ancestry rather than to "people of colour" (i.e., so-called non-Whites) in general. This term is often viewed as derogatory and is therefore used here in a circumspect manner.

\section{References}

Andersen, E.S., M. Brizuela, B. DuPay, B. and L. Gonnerman. 1999. Cross-linguistic evidence for the early acquisition of discourse markers as register variables. Journal of Pragmatics 31: 1339-1351.

American Speech and Hearing Association. 1997-2009. Hearing screening. Available online at http://www.asha.org/public/hearing/testing/

Bergerson, J. 2002. An etymology of Afrikaans mos. Tijdschrift voor Nederlandse Taal-en Letterkunde 118(4): 335-341.

Beukes, V. 2007. Die evaluering van 'n nuutgeskepte luisterprogram vir postbeginner studente [The evaluation of a newly devised listening porgram for postbeginner students]. MA thesis, Stellenbosch University. Available online: http://ir.sun.ac.za/dspace/bitstream/10019/590/1/Beukes,+V.pdf. (Accessed 5 Augustus 2008).

Biber, D. 1988. Variation across speech and writing. Cambridge, UK: Cambridge University Press.

Carstens, W.A.M. 1997. Afrikaanse tekslinguistiek [Afrikaans text linguistics]. Pretoria: J.L. van Schaik Akademies.

Craig, H.K. and T.M. Gallagher. 1988. The development of pragmatic connectives: 4- and 6year-old comparisons. Journal of Pragmatics 12: 175-183.

Escalera, E.A. 2009. Gender differences in children's use of discourse markers: Separate worlds or different contexts? Journal of Pragmatics 41(12): 2479-2495.

Fraser, B. 1999. What are discourse markers? Journal of Pragmatics 31: 931-952. 
Furman, R. and A. Özyürek. 2007. Development of interactional discourse markers: Insights from Turkish children's and adults' oral narratives. Journal of Pragmatics 39: 17421757.

Gallagher, T.M. and H.K. Craig. 1987. An investigation of pragmatic connectives within preschool peer interactions. Journal of Pragmatics 11: 27-37.

Hick, R.F., N. Botting and G. Conti-Ramsden. 2007. Short-term memory and vocabulary development in children with Down syndrome and children with specific language impairment. Developmental Medicine and Child Neurology 47(8): 532-538.

Klop, D. and S.K. Tuomi. 2007. The persistence of language disorders in a group of disadvantaged grade 3 learners. The South African Journal of Communication Disorders 54: 59-66.

Kruger, A. 2004. The role of discourse markers in an Afrikaans stage translation of The Merchant of Venice. Journal of Literacy Science 20(3/4): 302-334.

Kyratzis, A. and S. Ervin-Tripp. 1999. The development of discourse markers in peer interaction. Journal of Pragmatics 31: 1321-1338.

Leonard, L.B. 1998. Children with specific language impairment. Cambridge and London: MIT Press.

Louwerse, M.M. and H. Hite Mitchell. 2003. Toward a taxonomy of a set of discourse markers in dialog: A theoretical and computational linguistic account. Discourse Processes 35(3): 199-239.

Meng, K. and S. Schrabback. 1999. Interjections in adult-child discourse: The cases of German HM and NA. Journal of Pragmatics 31: 1263-1287.

Müller, S. 2005. Discourse markers in native and non-native English discourse. Amsterdam: John Benjamins Publishing Company.

Norrick, N.R. 2001. Discourse markers in oral narrative. Journal of Pragmatics 33: 849-878.

Rice, M.L. 2003. A unified model of specific and general language delay: Grammatical tense as a clinical marker of unexpected variation. In Y. Levy and J. Schaeffer (eds). Language competence across populations. Toward a definition of specific language impairment. Mahwah, NJ: Lawrence Erlbaum Associates. pp. 63-95.

Rice, M.L., S.M. Redmond and L. Hoffman. 2006. Mean length of utterance in children with specific language impairment and in younger control children shows concurrent validity and stable and parallel growth trajectories. Journal of Speech, Language, and Hearing Research 49: 793-808.

Rice, M., K. Wexler and S. Herschberger. 1998. Tense over time: The longitudinal course of tense acquisition in children with specific language impairment. Journal of Speech, Language, and Hearing Research 41: 1412-1431.

Roberge, P. 2002. The modal elements mos and maskie in Cape Dutch. Journal of Language Sciences 24(3-4): 397-408.

Schiffrin, D. 1987. Discourse markers. Cambridge: Cambridge University Press.

Stark, R.E. and P. Tallal. 1981. Selection of children with specific language deficits. Journal of Speech and Hearing Disorders 46: 114-122. 